\title{
CENÁRIOS DO CURRÍCULO DE MATEMÁTICA NA EDUCAÇÃO INFANTIL SOB $O$ OLHAR DAS PROFESSORAS DOS CEMEI
}

\author{
MATHEMATICAL CURRICULUM SCENARIOS IN CHILD \\ EDUCATION UNDER VISION OF TEACHERS OF CEMEI
}

\section{ESCENARIOS DEL CURRICCULO DE MATEMÁTICA EN LA EDUCACIÓN INFANTIL BAJO LA VISIÓN DE LOS PROFESORES DE LOS CEMEI}

\author{
FRANCELY APARECIDA DOS SANTOS ${ }^{1}$ \\ GILBERTO JANUARIO²
}

\section{RESUMO}

0 artigo situa-se no campo de estudo sobre currículos de Matemática, no qual apresentamos resultado de uma pesquisa que investigou a compreensão revelada por um grupo de professoras da Educação Infantil em relação à Matemática e ao seu currículo. Os dados de análise referem-se à colaboração de oito professoras, coletados a partir de entrevista semiestruturada. Trata-se de um estudo de caso, em que o marco teórico se reporta ao currículo como proposta de formação e constituição de identidades; à Matemática como instrumento que contribui para o desenvolvimento das crianças; às crenças e concepções acerca de currículo e do papel da Matemática nas práticas de ensinar e aprender. Os resultados indicam que as professoras não têm dificuldades de identificar como 0 currículo de Matemática está inserido na prática cotidiana de sua própria atuação em sala de aula; que as dificuldades estão relacionadas à busca, planejamento e elaboração das atividades cotidianas relativas à Matemática.

Palavras-chave: Educação Matemática. Currículos de Matemática. Educação Infantil. Crenças e Concepções.

\section{ABSTRACT}

The article is located in the mathematics curriculum study field, in which we present results of a research that inquires the comprehension revealed by a group of Child Education teachers regarding Mathematics and its curriculum. It's a study case, in which the theorical mark reports itself to the curriculum with a proposal of formulation and constituition of identities; Mathematics itself as na instrument that contributes to children developments; the beliefs and conceptions about the curriculum and the role of Mathematics in the practices of learning and teaching. The results indicates that the teachers do not have difficulties in identifying how the Mathematics curriculum is inserted in the everyday practice and its own role in the classroom; that the difficulties about the search, planning and elaboration of everyday activities are related to Mathematics.

Keywords: Mathematics Education. Mathematics Curriculum. Child Education. Beliefs and Conceptions.

\section{RESUMEN}

El artículo se encuentra en el campo de estudio sobre currículos de Matemática, en el que presentamos el resultado de una investigación que investigó la comprensión revelada por un grupo de maestros de Educación Infantil en relación a la enseñanza de las Matemáticas y su currículo. Los datos de análisis se refieren a la colaboración de ocho

1 Doutora em Educação. Professora do Programa de Pós-Graduação em Educação da Universidade Estadual de Montes Claros. E-mail: francely.santos@unimontes.br. Orcid: http://orcid.org/0000-0002-0521-1910.

2 Doutor em Educação Matemática. Professor da Universidade Federal de Ouro Preto. Professor Colaborador do Programa de Pós-Graduação em Educação da Universidade Estadual de Montes Claros. E-mail: januario@ufop.edu.br. Orcid: http://orcid.org/0000-0003-0024-2096. 
maestros, recopilados de entrevistas semiestructuradas. Es un estudio de caso, en el cual el marco teórico se refiere al currículo como una propuesta para la formación y constitución de identidades; las Matemáticas como instrumento que contribuye al desarrollo de los niños; a las creencias y concepciones sobre el currículo y el papel de las matemáticas en las prácticas de enseñanza y aprendizaje. Los resultados indican que los maestros no tienen dificultades para identificar cómo se inserta el currículo de Matemática en la práctica diaria de su propio desempeño en el aula; que las dificultades están relacionadas con la búsqueda, planificación y elaboración de las actividades diarias relacionadas con las matemáticas.

Palabras-clave: Educación Matemática. Currículos de Matemática. Educación Infantil. Creencias y Concepciones.

\section{DO CONTEXTO DA FALA}

A formação inicial de professores que ensinam Matemática sempre esteve no centro da discussão de especialistas dos campos da Educação e Educação Matemática. Em sua pesquisa de doutorado, Curi (2004) abordou a formação das professoras a partir da análise do currículo de Matemática presente nos cursos de Pedagogia, chegando à conclusão que os conhecimentos matemáticos, os conhecimentos sobre currículo e aqueles referentes aos modos de ensinar, têm abordagem insuficiente para repertoriar as alunas, futuras professoras, e sua prática em sala de aula.

Na compreensão de Pires (2012), esses conhecimentos precisam ser objeto de discussão e tema de estudo de ações de formação continuada, sobretudo ao engajar as professoras em práticas formativas que têm como objetivo a ampliação de seus conhecimentos do currículo e da Matemática, em especial, dos conceitos/ideias que fazem parte dos programas de ensino que essas profissionais colocam em prática em situações de aula.

Em nossa experiência com formação de professoras que ensinam Matemática na Educação Infantil, temos observado que o conhecimento que essas profissionais têm de currículo e de Matemática muitas vezes não é suficiente para compreender a coerência entre o planejamento, os materiais de apoio e o trabalho a ser realizado em situações de aula. Ou, ainda, a visão que essas professoras têm de aspectos que envolvem o processo educacional influenciam a forma como se relacionam com 0 conhecimento e o mobilizam no desenvolvimento curricular.

0 que chamamos de visão, Gómez-Chacón (2003) discute como sendo crenças e concepções, as quais implicam os conhecimentos e determinam as atitudes das professoras ao criar e desenvolver situações que oportunizam a seus alunos a construção de aprendizagens. Assim, os modos de ver e conceber o currículo, a Matemática, os materiais de apoio e suas atitudes em relação ao desenvolvimento curricular é fruto de como as professoras creem e concebem os princípios e objetivos da Educação e, ainda, como se compreendem como agentes nas práticas educativas.

Nesse sentido, no desenvolvimento curricular, as crenças e concepções agem sobre as formas como as professoras mobilizam seus conhecimentos ao se relacionar com os elementos dos processos de ensino e de aprendizagem: objetivos de ensino; organização e seleção dos conteúdos; escolha de materiais de apoio; gestão da aula; conhecimentos e hipóteses manifestadas por seus alunos; e tempos e espaços. Esse relacionamento implicará a criação das condições que oportunizarão os alunos a formar os conceitos e a construir suas aprendizagens.

Consideramos importante 0 conhecimento a respeito da concepção que professoras têm do currículo e da Matemática, por ser essa concepção que molda as práticas de ensinar e de aprender, portanto, que molda as oportunidades criadas para que os alunos possam se desenvolver, pelo 
processo escolar, como sujeitos autores de suas aprendizagens. Quando tomado em um processo problematizador da prática, esse conhecimento colabora para o design curricular das ações de formação, seja inicial ou continuada, uma vez que indica aspectos da aprendizagem das professoras precisam ser ampliados; temas que requerem ser abordados; práticas a serem tematizadas; e crenças e concepções que podem ser (re)significadas.

Esse entendimento nos levou a desenvolver uma investigação que tem por objetivo analisar os fundamentos teórico-metodológicos que embasam o currículo de Matemática e as práticas pedagógicas das professoras da Educação Infantil, quando essas planejam e ministram aulas de Matemática. Neste artigo, focamos a analisar dados e a discutir sobre o conhecimento que professoras que atuam na Educação Infantil expressam ter sobre currículo e Matemática.

A partir dessa contextualização, na próxima seção é apresentado o procedimento metodológico. Na seção seguinte, textualizamos a análise e discussão. 0 artigo é finalizado com nossas considerações acerca do recorte da investigação aqui retratado.

\section{DO PROCESSO DA FALA}

Entendemos que o processo formativo, oportunizado pelo sistema educacional, é um desafio - e uma responsabilidade - para quem ensina e para quem aprende. Na Educação Básica, especialmente na Educação Infantil e nos primeiros anos do Ensino Fundamental, uma preocupação das professoras é a criação de condições que promovam o desenvolvimento das crianças e o letramento nas diferentes disciplinas, uma vez que são essas condições que levam as crianças a ampliar o que sabem como senso comum a partir do contato com o conhecimento proposto pelos currículos (SANTOS, 2020). No Ensino Superior, especialmente no curso de Pedagogia, uma preocupação dos professores-formadores é o desenvolvimento do conhecimento profissional docente, o que envolve a ampliação de seus conhecimentos, a (re)construção de sentidos e significados dados à educação e a (des)contrução de crenças e concepções, dentre elas, sobre currículos, Matemática e seu ensino.

0 planejamento e a realização de práticas formativas que oportunizem esse desenvolvimento profissional podem ser potencializados a partir do que se sabe sobre conhecimento que alunas e professoras que atuarão/atuam na Educação Infantil têm de currículo e de Matemática, dentre outros conhecimentos relevantes para balizar essas práticas. Desse modo, parte da pesquisa aqui retratada teve como propósito investigar a compreensão revelada por um grupo de professoras da Educação Infantil em relação à Matemática e ao currículo de Matemática. 0 que chamamos de compreensão aqui tem a conotação dos modos de ver e conceber, de expressar aquilo que faz sentido para si e pode ser oculto para o outro. Parafraseando Saviani (2011), é importante "mostrar a face visível da lua, isto é, reiterar o cotidiano, mas mostrar a face oculta, ou seja, revelar os aspectos essenciais das relações sociais que se ocultam sob os fenômenos que se mostram à nossa percepção imediata" (p. 201).

De abordagem qualitativa, este trabalho trata de uma investigação na perspectiva do estudo de caso, uma vez que a pesquisa aqui retratada refere-se a sujeitos e contextos que fazem parte de nossa prática como formadores de professoras e que, ao apresentar o que sabem sobre currículo e Matemática, procura mobilizar no leitor suas compreensões sobre esses temas (MERRIAM, 1998). Como nos esclarece André (2008) ao abordar pesquisas do tipo estudo de caso, a nossa opção ancora-se na compreensão da ação educativa que colabora para o desenvolvimento profissional docente em Matemática. No âmbito do estudo de caso, partimos da análise de dados e resultado advindos de um grupo reduzido de sujeitos para pensarmos em estratégias de formação de um grupo maior, 
no nosso caso, turmas de alunas que cursam Pedagogia ou grupos de professoras que participam de ações de formação continuada.

A pesquisa contou com a colaboração de oito professoras ${ }^{3}$ que atuam em turmas de crianças de cinco anos de idade, em dois Centros Municipais de Educação Infantil (CEMEI) na cidade de Montes Claros, região Norte de Minas Gerais. A escolha por essas professoras se deu a partir de nosso contato com a equipe gestora desses CEMEI, o que viabilizou nosso acesso e consulta às profissionais.

A coleta de dados se deu pela realização de entrevistas semiestruturadas, ocorridas no período de setembro a dezembro de 2019, para as quais foi enviado, previamente, um roteiro. Com as entrevistas, nosso propósito foi 0 de construir tessituras por meio das falas das professoras acerca do currículo de Matemática de forma mais contextualizada. As entrevistas foram gravadas, resguardando os devidos cuidados éticos, e transcritas com posterior envio a cada participante para leitura, ajuste em alguma resposta e autorização de sua utilização.

Para resguardar as identidades das professoras participantes, atribuímos uma ID - P1, P2, P3, P4, P5, P6, P7, P8 - a qual passaremos a fazer referência. No Quadro 1, apresentamos a caracterização e o perfil profissional das professoras participantes.

Quadro 1 - Caracterização das professoras participantes.

\begin{tabular}{|c|l|c|c|}
\hline Professora & \multicolumn{1}{|c|}{ Formação Acadêmica } & $\begin{array}{c}\text { Tempo de atuação } \\
\text { na Educação }\end{array}$ & $\begin{array}{c}\text { Tempo de atuação na } \\
\text { Educação Infantil }\end{array}$ \\
\hline P1 & $\begin{array}{l}\text { Pedagogia / Pós-Graduação Lato Sensu em Educação Inclusiva, Supervisão } \\
\text { e Inspeção }\end{array}$ & 9 anos & 9 anos \\
\hline P2 & $\begin{array}{l}\text { Pedagogia / Pós-Graduação Lato Sensu em Alfabetização, Letramento e } \\
\text { Linguagem Matemática }\end{array}$ & 8 anos & 8 anos \\
\hline P3 & $\begin{array}{l}\text { Normal Superior e Serviço Social / Pós-Graduação Lato Sensu em Docência } \\
\text { do Ensino Superior em EAD e em Psicopedagogia Clínica e Institucional }\end{array}$ & 20 anos & 15 anos \\
\hline P4 & $\begin{array}{l}\text { Normal Superior e Pedagogia / Pós-Graduação Lato Sensu em Supervisão } \\
\text { Escolar }\end{array}$ & 19 anos & 15 anos \\
\hline P5 & $\begin{array}{l}\text { Pedagogia / Pós-Graduação Lato Sensu em Educação Infantil } \\
\text { P6 }\end{array}$ & $\begin{array}{l}\text { Pedagogia / Pós-Graduação Lato Sensu em Educação Inclusiva e em } \\
\text { Alfabetização, Letramento e Linguagem Matemática }\end{array}$ & 19 anos \\
\hline P7 & $\begin{array}{l}\text { Normal Superior / Pós-Graduação Lato Sensu em Educação Especial, em } \\
\text { Educação Infantil e em Supervisão Educacional }\end{array}$ & 25 anos & 9 anos \\
\hline P8 & $\begin{array}{l}\text { Pedagogia / Pós-Graduação Lato Sensu em Educação a Distância, em } \\
\text { Educação Infantil e em Atendimento Educacional Especializado }\end{array}$ & 11 anos & 2 anos \\
\hline
\end{tabular}

Fonte: Dados da Pesquisa.

Ao determos nosso olhar para o Quadro 1, é possível observar que as professoras têm entre 8 e 20 anos de experiência de docência, período esse do qual de 2 a 15 anos são na Educação Infantil. Embora P8 tenha pouco tempo de atuação nesse nível de ensino, 2 anos, ela apresenta um tempo considerável de docência na Educação Básica. 0 restante do grupo podemos dividir em dois conjuntos, os quais apresentam certa homogeneidade cada um: aquele das professoras com maior tempo de experiência - P3, P4 e P7 - e o conjunto daquelas que tem um tempo médio de atuação, formado por P1, P2, P5 e P6.

3 A partir do aceite em colaborar, foi entregue e assinado o Termo de Consentimento Livre e Esclarecido (TCLE). 0 projeto foi submetido ao Comitê de Ética em Pesquisa da Universidade Estadual de Montes Claros, aprovado conforme parecer consubstanciado de n. 3.332.790. 
Em relação à presença da Matemática na Educação Infantil e 0 seu papel na formação das crianças, parte do grupo de professoras presenciou o primeiro movimento de reorientação curricular quando da publicação do Referencial Curricular Nacional para a Educação Infantil, em 1996, como é o caso de P3, P4, P5, P6 e P7. Embora quatro delas tenha iniciado sua carreira após a publicação do Referencial, todas tiveram suas primeiras experiências na efervescência das inovações apresentadas pelo documento. Recentemente, em dezembro de 2017, a publicação da Base Nacional Comum Curricular, versão para a Educação Infantil e Ensino Fundamental, proporcionou às oito professoras a inserção em novo movimento de reorientação curricular para a primeira fase de escolarização das crianças.

Tomar a publicação desses dois documentos e outros elaborados pela Secretaria Municipal de Educação de Montes Claros implica considerar que essas professoras, com maior ou menor envolvimento, puderam se engajar em estudo sobre propostas de abordagem da Matemática e o papel dessa disciplina para a formação das crianças. Assim, não é por ausência de prescrições ou de experiência que essas professoras possam alegar algum tipo de dificuldade para compreender como a Matemática se constitui como ferramenta e linguagem (SANTOS, 2020) nas práticas que oportunizam a educação das crianças. Sobre esse aspecto, Curi (2004) e Gómez-Chacón (2003) nos ajudam a compreender que as crenças e concepções manifestadas pelas professoras, conscientemente ou não, delineiam suas ações ao planejar e realizar as práticas, incidindo sobre a leitura e interpretação das orientações curriculares, a escolha dos materiais de apoio e a organização de tempos e espaços. Sobre esse aspecto, Fiorentini e Lorenzato (2006) ponderam que "o conhecimento e as crenças dos professores transformam-se continuamente e afetam, de modo significativo, a forma como os professores organizam e ministram suas aulas" (p. 47).

Ao serem questionadas sobre o que representa a Matemática, as professoras mostram em suas respostas a ausência do significado apresentado nos documentos curriculares ou em obras lidas em alguma fase de sua formação. As respostas restringem-se às percepções pessoais, para as quais verbalizam suas dificuldades e reconhecem as diferentes práticas sociais como contexto onde a Matemática está inserida, conforme podemos observar nos excertos seguintes.

Como eu poderia te explicar isso? 0 que é a Matemática pra mim? É essa questão que envolve números, quantidade, a passagem do tempo, calendário, tudo isso que está ao nosso redor e que a criança tem contato, como também nos rótulos, é em todos os lugares onde ela vê números, e por aí vai... mas confesso que trabalho menos a Matemática e que a vinda de sua pesquisa para a escola, me força a trabalhar mais com ela... (P1)

Olha... eu falo por mim, eu não sei como poderia te acrescentar, mas eu vou te falar por experiência. Na verdade, eu acho que, eu me avalio assim, quando veio a sua pesquisa, eu fiquei preocupada, pois particularmente, às vezes, percebo que eu trabalho pouco a Matemática. Tem uma cobrança muito grande em cima da alfabetização que a gente acaba que foca muito mais na alfabetização. (P3)

A Matemática está em tudo, ela é bem abrangente, então você trabalha com a Matemática a todo o momento e a todo instante. Desde a hora que você chega para contar as crianças com eles, você já está fazendo, usando a Matemática. Que os números estão inseridos em todo momento e em todo lugar. Então a Matemática, realmente é fácil de ser trabalhada por esse motivo, mas a gente preocupa muito mais com a parte de oral e escrita. (P7) 
Embora considerem a Matemática importante, para essas professoras ela não tem sido presente em suas aulas. A preocupação na alfabetização das crianças é 0 que determina 0 que será proposto nas situações de aprendizagem e, assim, são priorizados conhecimentos relativos à Língua Portuguesa. Como concepção, pratica-se o currículo disciplinar o qual sistematiza e organiza os conteúdos em especialidades, organizado na lógica disciplinar (BEANE, 2003). Essas professoras revelam não conceber a Matemática como ferramenta que colabora para o processo de alfabetizar e de desenvolver competências leitoras e escritoras, como destaca (DANYLUC, 2015; SANTOS, 2015).

Mesmo explicitando ter consciência que pouco abordam Matemática, as professoras revelam não planejar suas aulas de modo que privilegie e dê igual importância aos conteúdos propostos nos documentos curriculares. A crença dessas professoras assenta-se na necessidade de primeiro ensinar a ler e a escrever e, em paralelo, ensina-se outros conteúdos. Diferentes das orientações presentes nos documentos, as práticas formativas oportunizadas às crianças assentam-se na tradicionalidade pedagógica, como seleção dos conteúdos, e na forma linear de organizá-los o que, para Pires (2000), ocasiona um conhecimento fragmentado, baseado na acumulação.

É importante externarmos o nosso entendimento de que professoras da Educação Infantil e seus modos de compreender a educação e aspectos/elementos a ela relacionados precisam ser acolhidos e respeitados. Por isso, adotamos como pressuposto básico o princípio que elas ensinam Matemática; agem com intencionalidade; analisam e interpretam a realidade a qual fazem parte; as decisões tomadas estão de acordo com os sentidos e significados que atribuem à Matemática; e as experiências advindas da docência personificam seus conhecimentos, reverberando o ensino e a abordagem matemática dada em situações de aprendizagem.

\section{O LUGAR DO CURRÍCULO DE MATEMÁTICA NA EDUCAÇÃO INFANTIL}

No Brasil, de forma geral, há poucas discussões que tratam das especificidades do currículo de Matemática na Educação Infantil em detrimento da literatura que aborda outros aspectos como estratégias didáticas e metodológicas ao tratar conceitos matemáticos ou aspectos do desenvolvimento profissional docente. As discussões presentes nos resultados de pesquisas pouco têm chegado ao conhecimento das professoras que estão no cotidiano das salas de aula. Por outro lado, poucas são as aulas de Matemática ocorridas na Educação Infantil que abranjam um planejamento sistematizado e intencional para as crianças (ALVARENGA, 2014; PRAD0 e AZEVEDO, 2012).

Temos por hipótese que a ausência de documentos oficiais que abordem as especificidades curriculares para esse nível de ensino tem contribuído para a pouca abordagem da Matemática na formação das crianças. Embora seja recente, a Base Nacional Comum Curricular (BNCC) pouco explora conhecimentos relativos à Matemática que são importantes para repertoriar as práticas das professoras que atuam na Educação Infantil.

Se por um lado na BNCC há pouca abordagem de Matemática para a Educação Infantil, seus processos de ensino e de aprendizagem e o desenvolvimento profissional docente para esse nível de ensino são temas de debates permanentes na comunidade acadêmica, na qual pesquisadores têm apresentado importantes resultados de pesquisa e socializado experiências, 0 que colabora para se pensar o processo de educar matematicamente. No âmbito das discussões, há 0 entendimento que as crianças da Educação Infantil precisam seguir uma rotina, pois ela as ajuda a construir raciocínios e hábitos que contribuem para o desenvolvimento do pensamento matemático. Nesse sentido, defendemos que essa rotina precisa, por parte das professoras, ser intencional, planejada, organizada e 
com bases teóricas e curriculares que auxiliem as crianças a crescer e se desenvolver de forma a se tornarem autônomas e organizadas, autoras de suas descobertas e aprendizagens.

Esse entendimento é também compartilhado por professoras que ensinam Matemática para as crianças da Educação Infantil, como revela P5 em sua entrevista:

Porque temos os conteúdos que temos que trabalhar com as crianças, às vezes eu sinto ao longo desse tempo, que muita coisa que a gente poderia fazer a gente não fez. Ou porque falta material, ou porque de repente você tem vontade de fazer, mas você acha que às vezes as crianças não dão conta, hoje eu percebo que as crianças dão conta sim. Você faz uma brincadeira de amarelinha, você registra. A criança já tem essa concepção. "Ah professora olha eu vi ali é sete", você viu 0 Davi ali quando o pirata perguntou "como nos vamos ao mercado?", ele falou "é rota da nossa escola" (P5 - entrevista em 2019).

0 excerto revela que a professora P5 tem consciência de um conjunto de conteúdos a ser trabalhado com as crianças, que requer estratégias diferenciadas de abordagem. Porém, a ausência de orientações curriculares que melhor explicitem o que e a forma de abordagem são impeditivos de maior presença de Matemática nas aulas. Ainda, a crença sobre uma base sólida de aprendizagens construídas anteriormente para se aprender novos conteúdo é outro aspecto que interfere e implica a redução de atividades de Matemática, bem como a crença que repousa sobre a necessidade de recursos, possivelmente artefatos manipulativos, para tornar o ensino mais significativo. No entendimento de Gómez-Chacón (2003), as crenças estão relacionadas com o comportamento dos sujeitos e influenciam na capacidade de agir. No caso das professoras, suas crenças interferem no modo de entender e criar condições para que as crianças aprendam Matemática.

Por outro lado, o conhecimento advindo da experiência ao ensinar, como destaca Tardif (2002), faz com que P5 compreenda que as crianças são capazes de aprender, mesmo com cenários muitas vezes adversos ao que se tem como expectativa ao planejar os períodos letivos.

No que se refere a documentos que apresentam orientações curriculares, esses norteiam as professoras no trabalho com as crianças, ao incitar o cuidado que se deve ter com elas e ao recomendar as práticas pedagógicas. Nesse sentido, tanto o Referencial Curricular Nacional da Educação Infantil (BRASIL, 1998) quanto a Base Nacional Comum Curricular (BRASIL, 2017) consideram a necessidade do engajamento docente no planejamento e realização de atividades que levem as crianças a conhecerem a si, reconhecer o contexto social, observar e explorar os objetos ao seu redor e, a partir disso, fazer descobertas e atribuir sentidos e significados à aprendizagem. No entanto, podem ser observadas nos documentos curriculares orientações que melhor detalhem o fazer pedagógico, como podemos observar no fragmento da entrevista da professora P3:

Acredito que currículo é um documento para nos orientar e dizer, qual é o caminho a seguir para chegar a tal objetivo. Acredito que seja basicamente isso. No final do ano eu tenho que chegar em algum lugar. Aí o currículo vai me dando direcionamento (P3 - entrevista em 2019).

A professora revela uma concepção de currículo comum a outros profissionais da educação, qual seja, de um documento prescritivo, o qual organiza e sistematiza o que será oportunizado às crianças, e aos alunos em geral, como situações de aprendizagem. A fala de P3 mostra o que alguns 
estudos (LIMA e JANUARI0, 2017; PIRES, 2012) tem revelado: embora as prescrições curriculares possam apresentar os objetivos da educação, sugerir abordagens didáticas e metodológicas, eles pouco contribuem para as práticas de sala de aula ao se ensinar Matemática, fato que leva as professoras a buscar em materiais de apoio, como livros didáticos e recursos semelhantes, propostas que melhor traduzam as suas necessidades ao desenvolver o currículo.

Embora essa concepção limitada de currículo possa ser criticada, a fala da professora P3 passa a fazer sentido quando analisamos documentos prescritivos. A título de ilustração, citamos a Base Nacional Comum Curricular (BNCC) em sua abordagem para a Educação Infantil. Esse documento de 472 páginas, limita as orientações referentes ao processo educacional para as crianças desse nível de ensino a 21 páginas, que se mostra insuficientes para tratar da complexidade da formação na Educação Infantil. Nesse documento, os objetivos de aprendizagem e desenvolvimento para as crianças são organizados em quatro campos de experiências, sendo a Matemática relacionada a Espaços, Tempos, Quantidades, Relações e Transformações.

Considerando o currículo de Matemática dos cursos de Pedagogia, estudados por Curi (2004), a defasagem de conhecimentos com que se formam as professoras e as próprias limitações das prescrições curriculares, as práticas de ensinar e aprender Matemática na Educação Infantil são comprometidas quando se toma como referência um conjunto de 22 objetivos que, embora sinalizem 0 que é esperado que as crianças construam de aprendizagem, pouco norteiam as professoras sobre organização, seleção e abordagem dos conteúdos e conceitos implícitos a eles.

Ao tomarmos como ponto de discussão que, na Educação Infantil, o propósito é que as crianças desenvolvam o pensamento matemático ao passo que se alfabetizam pela Matemática, na perspectiva do letramento (SANTOS, 2015), a insegurança que a professora P3 apresenta, juntamente com outras professoras, se justifica pela ausência de abordagem, na BNCC, de orientações que melhor explicitem o trabalho no cotidiano escolar. Desse modo, o principal documento oficial que orienta as aulas de alfabetização matemática, nas turmas de Educação Infantil, mostra-se inconsistente em aspectos que ajudem no planejamento e organização da rotina diária, bem como a didática a que essas crianças precisam ser inseridas. Como consequência, os materiais de apoio utilizados pelas professoras podem ancorar-se em concepções teóricas e metodológicas que divergem dos princípios e objetivos do processo de alfabetização matemática subjacentes na Base Nacional Comum Curricular, ou outro documento prescritivo.

Porque eu acho que na educação infantil, a Matemática é um pouco assim... em si eu achava que o próprio município poderia ter um envolvimento maior com ela, pois as outras linguagens a gente aborda mais, e quase não temos orientações sobre a Matemática. Numa visão geral, quando você fala assim, linguagem oral e escrita, quando você vai responder um questionário da educação infantil, a primeira coisa que aborda é sobre a linguagem oral e a linguagem escrita. Tudo bem, se o aluno consegue ler e escrever ele vai conseguir raciocinar matematicamente. Mas na educação infantil as crianças elas precisam fazer pois é fazendo que elas aprendem, elas precisam experimentar para aprender. Então hoje vemos a maioria das crianças, até mesmo adolescentes que conhecem a Matemática como um "bicho de sete cabeças". Eu conheço pessoas adultas não gostam de Matemática, porque lá "na raiz", na educação infantil, deixou passar alguma coisa (P6 - entrevista em 2019). 
A Matemática é experiência é vivencia que os alunos e todos nós temos, constantemente em nosso dia a dia, através de nossa vivência mesmo, do que eu vivo, do que eu como, do que eu visto. Os números estão em todas as partes, a quantidade, o tamanho, a relação com a Matemática na educação infantil é voltada para essa questão aliada ao brincar, ao lúdico e dessa relação do que a criança vivencia no cotidiano, no seu dia a dia. Caso o sentimento em relação a matemática eu te falei, eu sinto o sistema municipal poderia providenciar mais jogos, mais oficinas, sabe... mais condições para que o professor tivesse mais recursos. E que eu não tivesse que procurar ou fazer, ou fomentar, sozinha, mais recursos. Esse é um sentimento. Porque por exemplo quando eu vou a uma capacitação que fala "ah vamos fazer isso, fazer aquilo, fazer aquilo", e eu tenho vontade de sair com tudo, tudo, tudo, pronto para meus alunos, mas esse tudo requer tempo, dinheiro, requer muitos outros pontos, muitos outros materiais e recursos. Mas o professor jamais vai querer algo que não o ajude no trabalho dele. Então todo o recurso é sempre bem vindo. Então um jogo a mais, uma coisa a mais, sempre é bem vinda. Às vezes eu acho que falta um pouquinho dessa questão do olhar cuidadoso mesmo, de ter recursos para que pudéssemos fazer um trabalho melhor. Que é algo que a escola preocupa agora mesmo as meninas da secretaria, que além do trabalho delas, também ajudam a confeccionar alguns jogos. A diretora, nos diz: "oh se vocês acharem um jogo que dá para todo mundo a gente deixa". As meninas da secretaria que tem uma carga horária maior, que são as auxiliares, ficam um pouco mais na hora do almoço produzindo os jogos. Elas sempre ajudam. Mas poderia ser mais sistematizado, se o sistema também ajudasse. Mas não adianta ficar chorando e reclamando aqui, não é? (P8 - entrevista em 2019).

Como documento concebido por uma instância externa à escola, as prescrições curriculares parecem pouco contribuir para o planejamento e a elaboração de atividades pelas professoras. Os excertos das entrevistas de P6 e P8 mostram uma necessidade de documentos locais que melhor retratem as necessidades das unidades educacionais; no caso, as professoras fazem referência a documentos que poderiam ser propostos no âmbito da Secretaria Municipal de Educação e que melhor orientariam as práticas de ensinar e aprender e apresentariam sugestões de materiais de apoio e práticas pedagógicas, tendo em vista a realidade da rede de ensino no âmbito do Município. Essas professoras - P6 e P8 - expressam a necessidade de o currículo ser um instrumento direcionador ao trabalho delas.

Uma pergunta fácil, mas de responsabilidade. Para mim, currículo é a organização da dinâmica da educação infantil. Desde a organização da rotina, da sala, como também dos conteúdos e das habilidades que serão desenvolvidas a partir de cada atividade trabalhada. Então é aquilo que norteia a educação infantil. Tudo que norteia educação infantil está dentro do currículo (P8 - entrevista em 2019).

Beane (2003), a discutir propostas de integração curricular, considera que, compreendido do modo como expressa a professora P8, o currículo pode limitar as práticas pedagógicas e restringir-se ao desenvolvimento de objetivos cognitivos das crianças, quando poderia ser um documento que oportunizasse às professoras - e à comunidade escolar - se repertoriar de conhecimentos e fundamentos da Educação para pensar em propostas educacionais que rompam com a lógica disciplinar, baseada no ensino de conteúdos organizados linearmente e com propostas espirais. Assim, 
o currículo poderia se configurar como uma proposta de educação que toma a escola como lócus de formação progressista para as crianças, na qual as professoras se assumem como agência do desenvolvimento curricular de Matemática (JANUARI0, 2020).

\section{O LUGAR DO CURRÍCULO NAS CONCEPÇÕES DAS PROFESSORAS}

Diferente da concepção de currículo que representa o status quo do poder e de seu sistema educacional, qual seja, o currículo tradicional, compreendido como técnico e linear, as ideias de currículo expressas neste artigo são aquelas que proporcionam às escolas e aos professores a oportunidade de, a partir de estudos, resultados de pesquisas e de documentos orientadores, conceber as propostas curriculares tendo como referência as práticas sociais das crianças e dos sujeitos da comunidade escolar e, ainda, o processo educacional que deseja construir e fazer parte.

Assim como Nacarato, Mengali e Passos (2009), compreendemos ser difícil definir "concepção", por ser, esse, um conceito polissêmico. Para essas autoras, pesquisadores que estudam essa temática atribuem a esse termo diferentes características e conotações: alguns fazem a distinção entre concepções e crenças; outros usam esses dois termos como sinônimos, ou como sinônimo de visões, ou ainda incluem as concepções e as crenças no sistema de conhecimentos dos professores. As ideias da professora P7 sobre 0 currículo revelam como ela concebe o processo formativo das crianças e mostra sua concepção acerca do que elas precisam aprender em termos de conteúdo. $\mathrm{Na}$ fala da professora P7, textualizada no excerto seguinte, podemos identificar a crença de que currículo é algo previsível, programado e limitado, o que torna possível, assim, o seu cumprimento em determinada época escolar, no caso, em uma faixa etária específica:

0 currículo é o que temos que ter na vida escolar das crianças, pois na sua faixa etária ela tem que aprender aquele currículo. Então aquilo que a gente tem que trabalhar, que é previsto, o que a criança de cinco anos no caso, precisa ter capacidade de aprender e como tem que suprir essa necessidade (P7 - entrevista em 2019).

Thompson (1992) compreende concepção como uma estrutura mental mais geral, que abrange concepções, conceitos, significados, proposições, regras, imagens mentais, preferências e gostos. A análise do excerto da entrevista de P7 mostra que sua concepção de currículo, como prática formativa, assemelha-se a conhecimento. No entender de Thompson (1992), há algumas características que os distinguem: as concepções podem ser defendidas em diversos níveis de convicção, independem de sua validade e não são consensuais, ou seja, pessoas diferentes pensam de forma diferente; o conhecimento, porém, está associado à certeza e à veracidade; 0 conhecimento é um "consentimento geral sobre procedimentos para avaliar e julgar suas validades e deve ter critérios envolvendo princípios de evidência" (p. 130).

Na concepção de Silva (1999), "o conhecimento que constitui o currículo está inextricavelmente, centralmente, vitalmente, envolvido naquilo que somos, naquilo que nos tornamos: na nossa identidade, na nossa subjetividade" (p. 15) e, por isso, o currículo, para além do processo e de questões de construção de conhecimento, é também uma questão de identidade e também de poder.

Responder à essa concepção requer de cada professora a ação de pensar sobre as próprias concepções acerca de Educação, de Matemática, e dos processos de ensino e de aprendizagem. Como destaca Gómez-Chacón (2003), as concepções, como sistemas de crenças, direcionam as 
práticas dos sujeitos; no caso das professoras, delimitam suas atitudes em relação à criação de condições que oportunizem às crianças a formar os conceitos matemáticos e a se desenvolver. Essas ideias são expressas pelas professas P1 e P2:

Para mim o currículo é o que nos embasa, e que nos orienta em nossos planejamentos, para nossas aulas (P1 - entrevista em 2019).

Currículo... Eu acredito que o currículo abrange tudo aquilo que começo a trabalhar, ou até mesmo planejar a partir das minhas aulas o que eu quero propor para os meus alunos. Então eu acredito que essa parte do currículo começa desde meu planejamento, aquilo que eu espero em sala de aula, aquilo que eu vou trabalhar dentro da minha rotina, na rotina que eu faço, na aula que eu estou almejando passar algum objetivo. E aquilo que também é proposto, o que eu quero que elas saibam. 0 que é me passado que eu devo desenvolver com elas. Então eu acredito que o currículo perpassa por tudo isso, desde quando eu preparo, dentro de sala de aula e aquilo que eu quero também. Não sei se tá certo, mas a ideia que eu tenho do currículo na educação infantil não tem como ter um currículo pronto e quadrado, entendeu? Porque muitas vezes eu tenho um currículo, eu falo "ah não, vai ser isso que eu vou planejar", mas eu chego dentro de uma realidade e vou ter que voltar um pouco pra trás, então eu acho que perpassa por tudo isso. Desde a minha rotina, atividade que eu realizei com meus alunos, aquilo que eu vou conseguir a um longo prazo (P2 - entrevista em 2019).

Para essas professoras, o currículo é compreendido como produto da cultura a qual as crianças estão inseridas. No caso de Matemática, o currículo revela-se pelas práticas e experiências das crianças ao interagir com o mundo, observar e perceber formas e propriedades que as ajudam a se situar e a conviver, ou ainda, que as levam a estabelecer relações e a construir sentidos e significados. Para o processo educacional, seja na Educação Infantil ou em outro nível, o currículo é implicado pelas demandas sociais das crianças e demais alunos. Nesse sentido, no processo de formação continuada pode-se ter maior liberdade e criatividade na concepção, planejamento e intencionalidades das práticas pedagógicas, as quais implicarão as rotinas diárias das crianças da Educação Infantil. Especialmente ao se propor ações de alfabetização matemática, na perspectiva do letramento, cria-se a possibilidade de uma identidade cultural curricular, discutida por Silva (1999) como

o conjunto daquelas características pelas quais os grupos sociais se definem como grupos: aquilo que eles são. Aquilo que eles são, entretanto, é inseparável daquilo que eles não são, daquelas características que os fazem diferente de outros grupos. Identidade e diferença são, pois, processos inseparáveis. A identidade cultural não é uma entidade absoluta, uma essência, uma coisa da natureza, que faça sentido em si mesma, isoladamente (p. 46).

Nessa perspectiva, o currículo não pode ser somente o que está apresentado nos documentos oficiais e na legislação que o organiza, mas, principalmente, no contexto cultural que a escola, as professoras e as crianças estão inseridas. Assim, pode-se responder, em primeiro lugar, para depois estabelecer o currículo oficial, quais são as características culturais da comunidade da qual eles fazem parte e se sentem pertencentes, como descreve Hall (2001) ao considerar que 
essas pessoas retêm fortes vínculos com seus lugares de origem e suas tradições, mas sem a ilusão de um retrocesso ao passado. Elas são obrigadas a negociar com as novas culturas em que vivem, sem simplesmente serem assimiladas por elas e sem perder completamente suas identidades. Elas carregam os traços das culturas, das tradições, das linguagens e das histórias particulares pelas quais foram marcadas. A diferença é que elas não são e nunca serão unificadas no velho sentido, porque elas são, irrevogavelmente, o produto de várias histórias e culturas interconectadas, pertencem a uma e, ao mesmo tempo a várias "casas" (e não a uma casa particular) (p. 88-89).

Nesse caso, aqui defendemos que o currículo, dentre eles o de Matemática, "não é um conceito, mas uma construção cultural. Isto é, não se trata de um conceito abstrato que tenha algum tipo de existência fora e previamente à experiência humana. É, antes, um modo de organizar uma série de práticas educativas" (GRUNDY, 1998, p. 11) e, por isso, é fundamental entender os contextos culturais da comunidade escolar e, também, o contexto legal que ela precisa seguir e se organizar.

No Brasil, 0 atendimento de crianças de zero a cinco anos, em creches e pré-escola, constitui direito assegurado pela Constituição Federal de 1988, consolidado pela Lei n. ${ }^{0}$ 9.394/96, Lei de Diretrizes e Bases da Educação Nacional (LDB), a qual estabelece em seu artigo 29 que "a Educação Infantil, primeira etapa da Educação Básica, tem por finalidade o desenvolvimento integral da criança até seis anos deidade, em seus aspectos físico, psicológico, intelectual e social, complementando a ação da família e da comunidade" (BRASIL, 1996).

Essa Lei introduziu uma série de inovações em relação à Educação Básica, dentre as quais a integração das creches nos sistemas de ensino, compondo, junto com as pré-escolas, a primeira etapa da escolarização. Essa Lei evidencia, também, o estímulo à autonomia das unidades educacionais na organização flexível de seu currículo e a pluralidade de métodos pedagógicos, desde que assegurem aprendizagem, reafirmaram os artigos da Constituição Federal acerca do atendimento gratuito em creches e pré-escolas (BRASIL, 2013).

Frente a todas essas transformações, a Educação Infantil vive um intenso processo de revisão de concepções sobre a educação de crianças em espaços coletivos, de seleção e fortalecimento de práticas pedagógicas mediadoras de aprendizagens e do desenvolvimento. Em especial, tem se mostrado prioritárias as discussões sobre como orientar 0 trabalho junto às crianças de até três anos em creches e como garantir práticas junto às crianças de quatro e cinco anos que se articulem, mas não antecipem processos do Ensino Fundamental (BRASIL, 2013). Desse modo, faz-se importante a discussão sobre currículo de Matemática, especialmente ao se pensar processos e propostas de ensino e de aprendizagem que compreendam o desenvolvimento do pensamento e da linguagem como aspectos relacionados à alfabetização matemática, bem como investigar concepções de professoras acerca de currículo como ação que pode balizar as práticas de formação continuada.

As instituições de Educação Infantil ainda se inscrevem no projeto de sociedade democrática, desenhado na Constituição Federal de 1988 (art. 30, inciso I), com responsabilidades no desempenho de um papel ativo na construção de uma sociedade livre, justa, solidária e socioambientalmente orientada, com função sociopolítica e função pedagógica a serem cumpridas (BRASIL, 2013).

Exercer tais funções significa, em primeiro lugar, que o Estado necessita assumir sua responsabilidade na educação coletiva das crianças, complementando a ação das famílias. Em segundo lugar, creches e pré-escolas constituem-se em estratégia de promoção de igualdade de oportunidades 
entre homens e mulheres, uma vez que permitem às mulheres sua realização para além do contexto doméstico. Em terceiro lugar, cumprir função sociopolítica e pedagógica das creches e pré-escolas implica assumir a responsabilidade de torná-las espaços privilegiados de convivência, de construção de identidades coletivas e de ampliação de saberes e conhecimentos de diferentes naturezas. Isso ocorre por meio de práticas que atuam como recursos de promoção da equidade de oportunidades educacionais entre as crianças de diferentes classes sociais no que se refere ao acesso a bens culturais e às possibilidades de vivência da infância. Em quarto lugar, cumprir função sociopolítica e pedagógica requer oferecer as melhores condições e recursos construídos histórica e culturalmente para que as crianças usufruam de seus direitos civis, humanos e sociais e possam se manifestar e ver essas manifestações acolhidas, na condição de sujeito de direitos e de desejos. Significa, finalmente, considerar as creches e pré-escolas na produção de novas formas de sociabilidade e de subjetividades comprometidas com a democracia e a cidadania, com a dignidade da pessoa humana, com o reconhecimento da necessidade de defesa do meio ambiente e com o rompimento de relações de dominação etária, socioeconômica, étnico-racial, de gênero, regional, linguística e religiosa que ainda marcam nossa sociedade (BRASIL, 2013). 0 nosso entendimento é que a Matemática se constitui como ferramenta, linguagem e pensamento que colaboram significativamente para esses processos. Nessa mesma sintonia, a professora P6 expressa:

Olha, eu particularmente amo! Quando eu saio da minha casa para trabalhar venho com satisfação, me sinto a cada, dia mais realizada. Porque educação infantil pra mim é, como se diz, a minha injeção de ânimo. Porque em nossa área está muito difícil, mas quando você vê a simplicidade das crianças e o retorno do seu trabalho, para mim não tem nem o que falar mais. Se resume em um ponto positivo, que é me fazer bem porque eu estou fazendo o que eu gosto que é ser professora da educação infantil (P6 - entrevista em 2019).

A Matemática, e tudo que ela proporciona à formação das crianças, é uma disciplina que apresenta conhecimentos que se revestem de instrumento de construção de autonomia e de identidade. Nesse caso, é preciso que na Educação Infantil seja planejado e organizado o que será trabalhado com as crianças, bem como as adequadas abordagens e estratégias metodológicas, tendo como propósito que elas desenvolvam o pensamento, construam argumentos, saibam se expressar, ampliem o raciocínio lógico-matemático e a capacidade de resolver problemas, como proposta inicial de construção da autonomia. Esse é o entendimento das professoras, como mostram os excertos seguintes.

Eu penso que a Matemática está inserida no cotidiano não só nosso mas da criança. E se eu for pensar a Matemática como eu pensava quando eu estudei eu vou mascarara-la, mas quando eu levo a Matemática de uma forma lúdica para a criança, eu consigo enxergar a Matemática com outro olhar. Eu consigo enxergar a Matemática como algo que vai possibilitar que meu aluno possa crescer, vai saber Matemática e vai aprender Matemática, igual a mim... Eu amo resolução de situação problema. E assim, vou possibilitar que minha criança possa pensar matematicamente (P2 entrevista em 2019). 
A Matemática para mim é tudo isso. Eu acho que a Matemática é uma ciência básica, para tudo, eu penso assim. 0 que você faz, o que você fala, o que você descobre... eu acho que a Matemática está em tudo (P5 - entrevista em 2019).

Ao trazermos Prado e Azevedo (2012) para nossa discussão, compreendemos a relação entre Matemática e criatividade, entre propostas curriculares e práticas pedagógicas que engajem professoras e crianças em um processo de construção de sentidos e significados a partir de um currículo que relacione os objetivos educacionais e as demandas sociais dos sujeitos da comunidade escolar. Assim, não estamos defendendo

a ausência de criatividade na Educação Infantil, ao contrário, que o professor dessa etapa possa exercer sua profissão docente, preocupando-se com a aprendizagem de seus alunos, independentemente da idade em que se encontram, sendo a criatividade, fundamental para a criança, não deve ser subtraída dos objetivos do currículo dessa etapa inicial da Educação Básica (PRAD0 e AZEVED0, 2012, p. 34).

Entendemos ser necessário pensar reflexivamente o sentido e significado do currículo de Matemática na Educação Infantil, pois ele tem sido um campo de controvérsias e de diferentes visões de criança, de família, de funções da creche e da pré-escola. No Brasil, nem sempre foi aceita a ideia de haver um currículo para a Educação Infantil, termo em geral associado à escolarização, tal como vivida no Ensino Fundamental e Médio, sendo preferidas as expressões "projeto pedagógico" ou "proposta pedagógica" (BRASIL, 2013).

A integração da Educação Infantil ao sistema educacional impõe à escola de Educação Infantil trabalhar com esses conceitos, diferenciando-os e articulando-os. A proposta pedagógica, ou projeto pedagógico, é o plano orientador das ações da instituição e define as metas que se pretendem para 0 desenvolvimento das crianças que nela são educadas e cuidadas, para as aprendizagens que se quer promover. No cotidiano, a instituição de Educação Infantil prepara seu currículo, que pode ser entendido como as práticas educacionais organizadas em torno do conhecimento e em meio às relações sociais que se travam nos espaços institucionais e que afetam a construção das identidades das crianças, como expressa a professora P1.

Para mim, educação infantil é espaço para aprender brincando, aprender de maneira lúdica, nada muito formatado e engessado. Tem que dar liberdade para a criança, e também não pode forçar, mas precisa orientar e fornecer oportunidades de aprendizagem, para ela sentir prazer no que esta aprendendo. Ela tem que ter o prazer em aprender senão, chegará ao fundamental já cansada e não querendo saber de nada, então, a educação infantil precisa ser trabalhada de forma prazerosa e lúdica (P1 - entrevista em 2019).

Por expressar o projeto pedagógico da instituição em que se desenvolve, englobando as experiências vivenciadas pela criança, o currículo se constitui um instrumento político, cultural e científico coletivamente formulado; é concebido como um conjunto de práticas que buscam articular as experiências e os saberes das crianças com os conhecimentos que fazem parte do patrimônio cultural, artístico, científico e tecnológico. Tais práticas são efetivadas por meio de relações sociais que as crianças, desde bem pequenas, estabelecem com as professoras e com as outras crianças e que 
afetam a construção de suas identidades. Intencionalmente planejadas e permanentemente avaliadas, as práticas que estruturam o cotidiano das instituições de Educação Infantil devem considerar a integralidade e indivisibilidade das dimensões expressivo-motora, afetiva, cognitiva, linguística, ética, estética e sociocultural das crianças, apontar as experiências de aprendizagem que se espera promover com elas e efetivar-se por meio de modalidades que assegurem as metas educacionais de seu projeto pedagógico. Nesse sentido, P7 considera que

a educação infantil vem evoluindo cada vez mais, às vezes ocorrem mudanças quando se muda a gestão do município. Com mudanças políticas de prefeito e de secretário de educação, na maioria das vezes, se muda muito as normas, a organização e as estruturas das escolas. Uns falam que não pode, e então vem o outro $e$ diz que o que não podia, agora pode. Então, para nós professores, para as crianças e para a escola, isso não tem uma sequência lógica. Antigamente, há uns 4 anos atrás, não podia alfabetizar criança, agora tem que alfabetizar. Então hoje em dia e com o mundo da informática, as crianças estão deixando de ser criança. Então perdendo a essência da infância, então a criança não sabe o que é brincar, além da utilização das tecnologias. E se a escola e o sistema político fazem modificações, mas se esquecem das crianças, nem sempre as mudanças políticas as ajudam a continuarem a ser crianças. Em nossa época tínhamos o brincar na rua, de amizades, hoje não, hoje as crianças tem brinquedos eletrônicos, celular, tablet e ficam cada um no seu canto, no seu mundo, com pouca interação. Então isso atrapalha bastante, apesar que tem seus benefícios. As crianças evoluem em outras áreas, mas na escola, amadurecem fora do tempo. Isso atrapalha bastante e deixa algumas fases da vida para trás, que são fundamentais principalmente a fase do brincar, que a educação infantil favorece. E nós vemos que o brincar na educação infantil é essencial e as crianças aprendem muito mais com brincadeiras, do que você só escrevendo no quadro ou no caderno, sem contextualizar. 0 registro é fundamental, mas depois de atividades que sejam significando para o aprendizado das crianças (P7 - entrevista em 2019).

A gestão democrática da proposta curricular precisa contar, na sua elaboração, com 0 acompanhamento e avaliação, tendo em vista o Projeto Político Pedagógico (PPP) da unidade educacional, com a participação coletiva de professores, demais profissionais da instituição, famílias, comunidade e das crianças, sempre que possível e à sua maneira. Na proposta do PPP, a organização curricular das disciplinas precisa ser definida, dando a cada uma delas o tempo e organização necessários aos processos de ensino e de aprendizagem das crianças.

Para pensar 0 currículo de Matemática, pode-se fazer 0 exercício de pensar quem são as crianças, de como elas podem aprender Matemática e de como a escola ensina Matemática a elas. A criança tem contato com a Matemática desde que nasce, pois, a partir desse momento, ela se insere numa sociedade da qual os números, as medidas, as formas, as grandezas e os espaços fazem parte. Mas, a partir do momento em que ela entra na escola, seja de Educação Infantil, seja de Ensino Fundamental, a criança se depara com outra maneira de aprender, diferente daquela vigente no convívio familiar, à qual estava frequentemente acostumada. Nesse sentido, Machado (1994) entende que para ampliar as possibilidades de sucesso no ensino de Matemática, é necessária "uma reaproximação entre seu significado e aquele que tinha originalmente - tudo que se pode aprender - que está 
intimamente relacionado ao desenvolvimento dos primeiros rudimentos da razão à fundamentação do raciocínio em todas as ciências" (p. 8).

Nesse entendimento, Leontiev (1998) considera que toda a vida da criança se reorganiza a partir da entrada no espaço escolar, por isso,

não podemos deixar de dar atenção a este momento na vida da criança. Todo o sistema de suas relações vitais se reorganiza [...] 0 essencial é que doravante as sua obrigações não são apenas para com os pais e o educador; são objetivamente obrigações relativas à sociedade [...] Ao fazer os seus deveres, a criança tem, pela primeira vez, sem dúvida, a impressão de fazer qualquer coisa verdadeiramente importante [...] Que diferença de suas ocupações e de seus jogos precedentes! (p. 289).

Sem a consideração da criança em sua condição infantil, as propostas curriculares podem atuar no vazio, na ausência de sentido. Assim, quando tratamos especificamente da organização do ensino de Matemática na Educação Infantil, é importante compreendermos que os conhecimentos dessa disciplina, como de qualquer outra área do conhecimento, é parte do universo da criança, mesmo antes de ela frequentar a escola. Essa compreensão se revela como preocupação para a professora P3:

Na verdade eu tenho ficado um pouco frustrada com a educação infantil pelos rumos que ela está tomando, como se fosse ensino fundamental, principalmente o trabalho com as crianças de 5 anos de idade. Talvez porque eu tenha começado muito nova, há muitos anos atrás, e eu tenho ficado assim meio preocupada. Eu posso estar errada, mas eu acho que a cobrança em cima da educação infantil tira um pouco da criança, tira a infância dela. Eu falo que estão usando o segundo período como se fosse o primeiro ano; para os meninos já chegarem no primeiro ano alfabetizados e não darem tanto trabalho, e isso tira a oportunidade de viver a infância e as experiências da educação infantil. $E$ tanto que eu trabalhei dois anos com turmas de segundo período e acabei indo para o do maternal... e retornei para o segundo período. Eu sempre falo: "Eu não concordo com isso, eu não concordo que o menino tem que saber isso na educação infantil, eu não concordo com isso". $E$ as vezes batemos de frente e isso cria um certo desconforto. Eu acho que é mais o lúdico, o brincar... entendeu? Eu acho que é deixar a criança aprender porque ela dá conta e não porque "eu preciso chegar naquele ponto no final do ano porque tem que ser assim”, sem levar em consideração, a criança; não eu acho que eu não tenha que trabalhar o que mandam, mas se a criança não aprendeu, ela tem 0 tempo dela e aprenderá (P3 - entrevista em 2019).

A fala da professora P3 mostra sua preocupação com o currículo proposto para a Educação Infantil, o qual tem priorizado um ensino conteudista, semelhante ao que ocorre nos Anos Iniciais do Ensino Fundamental, em detrimento de práticas que procuram levar as crianças às descobertas de si e do mundo por meio de atividades lúdicas. Nesse sentido, pesa sobre o currículo de Matemática, assim como de outras disciplinas, a inflexibilidade e a rigidez de um programa de conteúdos a serem cumpridos, com objetivos bem delineados, como se a Educação Infantil fosse uma etapa escolar preparatória para o Ensino Fundamental. Aqui não criticamos ações planejadas e sistematizadas ao trabalhar o processo de escolarização das crianças, mas evidenciamos os sentimentos da 
professora P3 em relação ao possível abandono de atividades que levem as crianças a desenvolver 0 pensamento, a criatividade e a fazer descobertas a partir de atividades que envolvam 0 experimento, 0 questionamento e a elaboração de hipóteses.

Entretanto, como alerta Moura (2007), isso não é suficiente para que a criança, de fato, aproprie-se dos conhecimentos matemáticos. Para que ela torne seu o conhecimento historicamente acumulado, é necessário que o mundo adulto intervenha. Trata-se de efetivar a mediação cultural e, desse modo,

devemos fazer com que a criança apreenda este conhecimento como parte de seu equipamento cultural para que possa intervir com instrumentos capazes de auxiliá-la na construção de sua vida. Trata-se de instrumentos que não são apenas utilitários, pois permitem que o sujeito os aprimore como 0 artesão que domina cada vez mais a técnica de execução de sua arte. No caso do filho do homem, é a busca da construção da vida (MOURA, 2007, p. 60).

A atividade de ensino, nessa perspectiva de conter o conteúdo e a forma, de ter um problema desencadeador e de possibilitar ao sujeito inserir-se no processo de aprendizagem de Matemática, passa a exigir que a Educação e a Matemática sejam contribuintes para 0 desenvolvimento humano. Assim, percebe-se a importância, no ato de educar, de ações conjuntas na escola para a criação de atividades de ensino que deem conta de se materializar como situações significativas e humanizadoras na área da Matemática.

Nos processos de ensino e de aprendizagem, a influência do que os professores compreendem como Matemática, muitas vezes, pode criar obstáculos para seu desempenho docente. As concepções se formam em um processo simultaneamente individual e social, e, em cada indivíduo, elas se constituem tanto por suas experiências pessoais e por sua história de vida como pela relação que ele estabelece com as outras pessoas. Nessa perspectiva, nossas ideias sobre Matemática são influenciadas por nossas experiências e, também, pelas representações sociais dominantes (PONTE, 1992; GÓMES-CHACÓN, 2003).

A prática pedagógica em Matemática precisa, de maneira predominante, estar fundamentada por uma determinada teoria pedagógica, isto é, uma pedagogia. Por consequência, nas entrelinhas das distintas pedagogias existem elementos teórico-metodológicos que devem elucidar aspectos pertinentes para a prática pedagógica, tais como: concepção de mundo, concepção de educação, relação entre professor e aluno, método de ensino (SILVA, 2019).

Os aspectos de ensinar e de aprender Matemática, na concepção tradicional, ganharam espaço no Brasil a partir da década de 1950. As instituições escolares trabalhavam com o método que ainda se faz presente na concepção de muitos professores, que incentivam 0 aluno durante 0 trabalho pedagógico a fazer uso da memorização, decorando os conteúdos, sem atribuir sentido ao que se aprende, como destacam Mundim, Ghelli e Oliveira (2017). Nos dias atuais, ainda encontramos esse tipo de trabalho pedagógico em sala de aula da Educação Infantil, tanto que temos algumas escolas que produzem ações destinadas a delinear comportamentos prontos para participação em vestibulares, chamadas de "Vestibulinhos." Nesse caso, essa prática que ocorre em algumas escolas diverge das ideias que a professora P4 tem acerca da Educação Infantil.

É a base de tudo, é o começo do ingresso na escola, ou de ficar estagnado e cansado, ou de tomar gosto pela escola. Acho que por isso a gente tem que fazer de uma 
forma em que a criança tenha, cada vez mais vontade de estudar, de ir pra escola, e não ficar aquela coisa massacrante, para que eles não percam o gosto pela escola (P4 - entrevista em 2019).

Sabemos que o processo de educar matematicamente é muito importante para o desenvolvimento da criança, uma vez que serve para aprimorar o desenvolvimento do raciocínio lógico e a capacidade de argumentar, compreender, interpretar, projetar, criar e atribuir significados para as mais diversas situações sociais, favorecendo, assim, a alfabetização matemática na perspectiva do letramento.

\section{CONSIDERAÇÕES}

Na Educação Infantil, as crianças estão inseridas em escolas que, por vezes, as professoras e os demais profissionais não as concebem como seres humanos de 0 a 5 anos de idade, muito menos que a Matemática tem elementos estruturais que podem ser inseridos nas rotinas didáticas e pedagógicas das crianças. Em alguns casos, a Matemática não é pensada como instrumento histórico, democrático, cultural e de aprendizagem para todas e todos, sem distinção.

Nesse contexto, destaca-se a importância social da atuação docente por se entender que, quando a professora tem consciência de seu papel, percebe a si e a criança como sujeitos ativos e interativos. Como consequência, estabelece-se um compromisso com a formação da criança e com a sua própria formação e desenvolvimento profissional.

A discussão aqui feita, fruto de um estudo que envolveu professoras que ensinam Matemática na Educação Infantil e parte de um projeto maior de pesquisa, teve como objetivo discutir o conhecimento que essas profissionais expressam sobre o currículo de Matemática. Nesse sentido, ao trazer à baila as falas textualizadas de um grupo de professoras, procuramos mostrar a importância de processos que investiguem as concepções dessas profissionais como sujeitos implicadas em propostas educacionais que pouco são reverberadas pelas prescrições curriculares.

Ao retomarmos o objetivo proposto para 0 artigo, 0 estudo mostrou que, se por um lado é importante e essencial a formação matemática para atuar na Educação Infantil, igualmente é relevante o estudo do campo do currículo e sua compreensão como projeto de poder que implica as práticas pedagógicas. Também, o currículo precisa ser compreendido como projeto de educação que traduz as demandas sociais das crianças e dos sujeitos que compõem a comunidade escolar.

Disso implica considerar que na formação inicial ou continuada, os saberes das professoras precisam ser contextualizados em práticas que reverberem sentidos e significados atribuídos pelas crianças em suas práticas, ao se relacionar em comunidade e ao se situar no mundo. A Matemática, como prática humana, além de ser compreendida como uma ciência, pode ser materializada em situações de aprendizagem como possibilidade para promover o desenvolvimento do pensamento e de ações para estar e conviver em sociedade. Portanto, o currículo de Matemática, especialmente na Educação Infantil, pode ser compreendido como projeto que oportuniza às crianças uma formação integral, que as capacita para ler e se situar no mundo.

Esse é o principal entendimento que as professoras participantes da pesquisa revelam ter sobre o currículo, em detrimento de propostas que concebem as práticas de educar matematicamente na Educação Infantil como modelo de escolarização para os Anos Iniciais do Ensino Fundamental. No entanto, ao analisar suas falas, é possível identificar pouco conhecimento sobre como a Matemática pode ser abordada nas práticas pedagógicas que envolvem atividades lúdicas. Ou seja, para essas 
professoras a Matemática é importante no currículo da Educação Infantil e contribui para as crianças desenvolver o pensamento, a criticidade, a curiosidade e a imaginação. Porém, há desconhecimento em relação aos diferentes conteúdos matemáticos e sua abordagem ao se criar as condições para que ocorra esse desenvolvimento. As falas das professoras, textualizadas nos excetos, mostram a recorrência a números e ao processo de contagem, incluído o pensamento aditivo de composição, como 0 conteúdo mais presente em seus planejamentos e práticas. Essas mesmas falas revelam a ausência de, por exemplo, abordagens referentes à exploração da localização espacial e ao reconhecimento de suas formas, e ao experimento com medidas.

Os resultados aqui apresentados convergem para aqueles que a pesquisa brasileira tem mostrado, qual seja, a importância de se investir em propostas de formação inicial e continuada que levem as professoras a desenvolver e ampliar seus conhecimentos profissionais em relação à Matemática e seu ensino. Sobretudo, mostra a importância de tomar as crenças e concepções dessas profissionais como elementos para balizar o design dessas propostas de formação.

\section{REFERÊNCIAS}

ALVARENGA, Vanessa Cristina. 0 impacto das políticas públicas no processo de profissionalização na Educação Infantil. In: SILVA, Maria Vieira; MEDINA, Sarita. (Org.). Trabalho docente e políticas educacionais para a Educação Infantil: desafios contemporâneos. Uberlândia: EdUFU, 2014, p. 77-100.

ANDRÉ, Marli Eliza Dalmazo Afonso. Estudo de caso em pesquisa e avaliação educacional. Brasília: Liber Livros, 2008.

BEANE, James A. Integraçãa curricular: a essência de uma escola democrática. Tradução de João Paraskeva. Currículo sem Fronteiras, v. 3, n. 2, p. 91-110, jul./dez. 2003.

BRASIL. Lei n. 9.394, de 20 de dezembro de 1996. Estabelece as diretrizes e bases da educação nacional. Brasília: Diário Oficial da União, 23 dez. 1996.

BRASIL. Ministério da Educação. Conselho Nacional da Educação. Diretrizes Curriculares Nacionais Gerais da Educação Básica. Brasília: MEC/CNE, 2013.

BRASIL. Ministério da Educação. Secretaria de Educação Básica. Base Nacional Comum Curricular: Educação Infantil e Ensino Fundamental. Brasília: MEC/SEB, 2017.

BRASIL. Ministério da Educação. Secretaria de Educação Fundamental. Referencial Curricular Nacional para a Educação Infantil. Brasília: MEC/SEF, 1998.

CURI, Edda. Formação de professores polivalentes: uma análise de conhecimentos para ensinar Matemática e de crenças e atitudes que interferem na constituição desses saberes. 2004. 278f. Tese (Doutorado em Educação Matemática) - Faculdade de Ciências Exatas e Tecnologias. Pontifícia Universidade Católica de São Paulo. São Paulo.

DANYLUK, Ocsana Sônia. Alfabetização matemática: as primeiras manifestações da escrita infantil. 5. ed. Passo Fundo: EdUPF, 2015.

FIORENTINI, Dario; LORENZATO, Sergio. Investigação em Educação Matemática: percursos teóricos e metodológicos. Campinas: Autores Associados, 2006. 
GÓMEZ-CHACON, Maria Inés. Matemática emocional: os afetos na aprendizagem matemática. Tradução de Daisy Vaz de Moraes. Porto Alegre: Artmed, 2003.

GRUNDY, Shirley. Producto o praxis del curriculum. 3. ed. Madrid: Morata, 1998.

HALL, Stuart. A identidade cultural na pós-modernidade. Tradução de Tomaz Tadeu da Silva e Guaracira Lopes Louro. Rio de Janeiro: DP\&A, 2001.

JANUARI0, Gilberto. Agência, affordance e a relação professor-materiais curriculares em Educação Matemática. Ensino em Re-Vista, Uberlândia, v. 27, n. 3, p. 1055-1076, set./dez. 2020.

LEONTIEV, Alexis Nikolaevich. Uma contribuição à teoria do desenvolvimento da psique infantil. In: VIGOTSKI, Lev Vygotsky; LURIA, Alexander Romanovich; LEONTIEV, Alexis Nikolaevich. Linguagem, desenvolvimento e aprendizagem. Tradução de Maria da Pena Villalobos. 6. ed. São Paulo: EDUSP, 1998, p. 59-83.

LIMA, Katia; JANUARIO, Gilberto. Princípios de integração de valores culturais ao currículo e a organização dos conteúdos em livros didáticos de Matemática. Educação Matemática Debate, Montes Claros, v. 1, n. 1, p. 76-98, jan./abr. 2017.

MACHADO, Nilson Jose. Matemática e Realidade. São Paulo: Cortez, 1994.

MERRIAM, Sharan B. Case study research in education. San Francisco: Jossey Bass, 1988.

MOURA, Manoel Oriosvaldo de. Matemática na infância. In: MIGUEIS, Marlene da Rocha; AZEVED0, Maria da Graça. (Org.). Educação Matemática na infância: abordagens e desafios. Vila Nova de Gaia: Gailivro, 2007, p. 39-64.

MUNDIM, Joice Silva Marques; GHELLI, Kelma Gomes Mendonça; OLIVEIRA, Guilherme Saramago de. 0 trabalho pedagógico com os saberes matemáticos na Educação Infantil. Cadernos da Fucamp, Monte Carmelo, v. 16, n. 28, p. 35-48, 2017.

NACARATO, Adair Mendes; MENGALI, Brenda Leme da Silva; PASSOS, Cármen Lúcia Brancaglion. A Matemática nos Anos Iniciais do Ensino Fundamental: tecendo fios do ensinar e do aprender. Belo Horizonte: Autêntica, 2009.

PIRES, Célia Maria Carolino. Currículo de Matemática: da organização linear à idéia de rede. São Paulo: FTD, 2000.

PIRES, Célia Maria Carolino. Educação Matemática: conversas com professores dos Anos Iniciais. São Paulo: Zapt, 2012.

PONTE, João Pedro da. Concepções dos professores de Matemática e processos de formação. In: PONTE, João Pedro da. (Org.). Educação Matemática: temas de investigação. Lisboa: IIE, 1992, p. 185-239.

PRAD0, Alessandra Elizabeth Ferreira Gonçalves; AZEVEDO, Heloisa Helena Oliveira de. Currículo para a Educação Infantil: argumentos acadêmicos e propostas de "educação" para crianças de 0 a 5 anos. In: ARCE, Alessandra; JACOMELI, Mara Regina Martins. (Org.). Educação Infantil versus Educação Escolar? Entre a (des)escolarização e a precarização do trabalho pedagógico nas salas de aula. Campinas: Autores Associados, 2012, p. 33-52.

SANTOS, Francely Aparecida dos. A literatura infantil como estratégia pedagógica no processo de alfabetização matemática. Ensino em Re-Vista, Uberlância, v. 27, n. 2, p. 546-571, maio/ago. 2020. 
SANTOS, Francely Aparecida dos. A Matemática como um texto. In: BRASIL, Secretaria de Educação Básica, Diretoria de Apoio à Gestão Educacional. Pacto Pela Alfabetização na Idade Certa: Alfabetização Matemática na perspectiva do letramento. Caderno 7. Brasília: MEC/SEB, 2015, p. 30-41.

SAVIANI, Dermeval. Antecedentes, origem e desenvolvimento da pedagogia histórico-crítica. In: MARSIGLIA, Ana Carolina Galvão. (Org.). Pedagogia histórico-crítica: 30 anos. Campinas: Autores Associados, 2011, p. 197-226.

SILVA, Matheus Bernardo. Fundamentos teórico-metodológicos da Pedagogia Histórico-Crítica: uma relação necessária entre história e filosofia. Educar em Revista, Curitiba, v. 35, n. 76, p. 199-218, jul./ago. 2019.

SILVA, Tomaz Tadeu. Documentos de Identidade: uma introdução às teorias do currículo. Belo Horizonte: Autêntica, 1999.

TARDIF, Murice. Saberes docentes e formação profissional. Tradução de Francisco Pereira. 4. ed. Rio de Janeiro: Vozes, 2002.

THOMPSON, Alba G. Teachers' beliefs and conceptions: a synthesis of the research. In: GROUWS, Douglas A. (Ed.). Handbook of Research on Mathematics Teaching and Learning. New York: Macmillan Publishing Company, 1992, p. 127-146.

RECEBIDO EM: 23 jun. 2020

CONCLUÍDO EM: 06 out. 2020 
